\title{
Optimasi Desain Paddock Stand Sebagai Sistem Statis dengan Menggunakan Finite Element Method
}

\author{
Optimization of Paddock Stand Design as a Static System using \\ Finite Element Method
}

\author{
Susastro $^{1}$,Alaya Fadlu Hadi Muhammad ${ }^{2}$, Aini lostari ${ }^{3}$, Yoga Ahdiat Fakhrudi ${ }^{4}$ \\ 1,2 Sekokasi, Universita Diponegoro \\ ${ }^{3}$ Teknik Mesin, Universitas Qomarudin Gresik \\ ${ }^{4}$ Mesin otomotif, Politeknik Negeri Madiun \\ 1,2 Jalan Hayamwuruk No.4 , Peleburan, Semarang, 50241, Indonesia \\ 3 Jalan Raya Bungah No.1, Gresik, Jawa Timur 61152 \\ ${ }^{4}$ Jalan Serayu No.84, Pandean, Taman, Madiun 63133 \\ email: susastro@live.undip.ac.id; alayad4rpm@lecturer.undip.ac.id; ainims31@gmail.com; \\ yoga@pnm.ac.id
}

DOI;

10.30595/jrst.v5i1.6023

Histori Artikel:

Diajukan:

$29 / 01 / 2020$

Diterima:

$10 / 12 / 2020$

Diterbitkan:

03/03/2021

\section{ABSTRACT}

Finite Element Method (FEM) merupakan suatu metode numerik yang dapat digunakan untuk menyelesaikan permasalah struktur yang complex dengan bantuan komputer. Banyak sekali kasus complex yang telah terselesaikan dengan metode ini. Metode finite element bahkan dapat digunakan untuk melakukan optimasi desain struktur, baik untuk permasalahan rekalkulasi dimensi maupun untuk pemilihan bentuk dari struktur. Dalam penelitian ini dilakukan optimasi dimensi dari krangka paddock stand serta diberikan juga beberapa variasi bentuk pada desain bentuk paddock stand. Adapun variasi bentuk yang diberikan adalah dengan mencoba untuk memberikan penyangga (RIB). Berdasarkan penelitian yang dilakukan menunjukan bahwa diameter optimal dari pipa paddock stand adalah sebesar $13 \mathrm{~mm}$. adapun lendutan terbesar yang diperoleh pada kondisi optimal adalah sebesar4 $\mathrm{mm}$, dengan nilai tegangan maksimal yang diperoleh sebesar 136,9 Mpa

Kata Kunci: Elemen hingga, stress, strain, MEH, fnite element

\begin{abstract}
Finite Element Method (FEM) is a numerical method that can be used to solve complex structural problems with the help of computers. Many complex cases have been resolved by this method. The finite element method can even be used to optimize structural design, both for dimensional recalculation problems (Metode \& Hingga, 2011) and for the selection of shapes from structures. In this research, the dimension optimization of the paddock stand frame is also done and also given a number of variations in the shape of the paddock stand design. The variations in the form given are trying to provide rib. Based on research conducted shows that the optimal diameter of the paddock stand pipe is $13 \mathrm{~mm}$. the largest deflection obtained at optimal conditions is $4 \mathrm{~mm}$, with the maximum stress value obtained at $136.9 \mathrm{Mpa}$.
\end{abstract}

Keywords: Finite Element, stress, strain, FEM 


\section{PENDAHULUAN}

Paddock stand merupakan suatu sandaran tengah tambahan, yang umum digunakan pada motor sport. Meningkatnya jumlah motor sport yang beredar di Indonesia berakibat pada semakin tingginya permintaan akan paddock stand. Paddock stand yang baik tentu tidak hanya berfungsi untuk mentegakkan motor, namun juga harus optimal baik dalam segi pemilihan material, desain dan dimensi (Fahd Riyal Pris, Budhi M Suyitno, \& Amin Suhadi, 2019; Metode \& Hingga, 2011). Desain dapat dikakatan optimal ketika produk tersebuh dapat menopang beban dengan baik sesuai dengan kriteria angka keamanan yang diberikan . Dengan desain yang optimal ini tentunya diharapkan dapat menghemat biaya produksi dan material yang digunakan.

Dalam melakukan desain struktur, tentu perlu dilakukan studi terkait kekuatan dari struktur terlebih dahulu. Untuk megetahui kekuatan dari struktur maka perlu untuk dilakukan uji karakteristik. Uji karakteristik dapat dilakukan dengan dengan menggunakan perhitungan maupun simulasi. Salah satu yang paling popular digunakan dalam meganalisa karakteristik dari sebuah desain struktur adalah dengan menggunakan Finite Element Method (FEM).

Metode FEM dapat digunakan untuk menyelesaikan permasalahn struktur yang complex pada benda padat, dan menghasilkan solusi berupa tegangan, regangan, defleksi, maupun fatigue life material (Fahd Riyal Pris et al., 2019). Banyak sekali kasus complex yang telah terselesaikan dengan metode ini. Seperti untuk mencari tegangan pada flexible pafement, getaran pada tiang penyangga mesin (Wandono \& Syah, 2017), tegangan maksimal pada pallet (Arief, 2014) dan as roda (Wandono, 2017) pesawat terbang, telah terselesaikan dengan sangat mudah. Metode finite element bahkan dapat digunakan untuk melakukan optimasi desain struktur, baik untuk permasalahan rekalkulasi dimensi (Metode \& Hingga, 2011) maupun untuk pemilihan bentuk dari struktur(Anggono et al., 2014; Covill et al., 2014; Fahd Riyal Pris et al., 2019; Ren, Yu, Zhao, Fan, \& Li, 2017)

Dari kelebihan finite element ini maka dalam penelitian ini dilakukan proses pemodelan tegangan paddock stand dengan kondisi statis. Pemodelan dilakukan dengan menggunakan Finite Element Method. Dalam penelitian ini dilakukan juga optimasi dimensi dari krangka paddock stand serta diberikan juga beberapa variasi bentuk pada desain bentuk paddock stand. Dengan demikian diperoleh bentuk serta dimensi paddock stand yang paling optimal.

\section{METODE}

Secara umum alur penelitian yang dilakukan ditunjukan pada Gambar 1. Penelitian ini dimulai dengan mencari refferensi terkait data berat kendaraan yang menggunakan paddock stand. Berdasarkan refferensi ditunjukan bahwa kapasitas mesin terbesar dari motor yang beredar Indonesia yaitu $250 \mathrm{cc}$. dari data yang ada menunjukan bahwa motor $250 \mathrm{cc}$ yang beredar di Indonesia memiliki bobot terberat $168 \mathrm{Kg}$ (Nugroho, 2018). dengan berasumsi bahwa $50 \%$ dari berat motor terletak pada roda belakang, maka gaya yang bekerja pada paddock stand adalah sebesar $84 \mathrm{Kg}$.

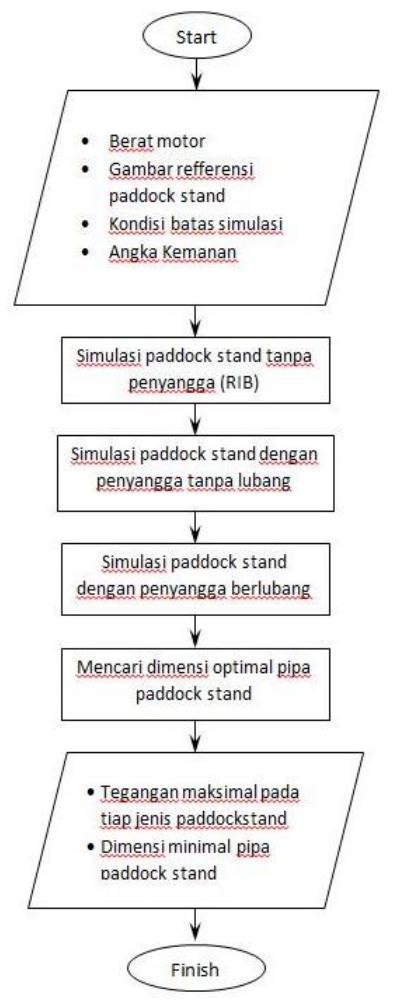

Gambar 1. Flowchart penelitian

Setelah diperoleh data terkait besar gaya yang bekerja paca paddock stand, langkah selanjutnya adalah mencari bentuk salah satu paddock stand yang sudah ada. Dari bentuk paddock stand yang sudah ada dilakukanlah 
proses penggambaran ulang sebagaimana pada Gambar 2. Pada kerangka paddock stand dilakukan beberapa variasi, diantaranya adalah dalam kondisi tanpa RIB (penyangga), dengan RIB dan dengan lubang pada RIB sebagaimana pada Gambar 2.

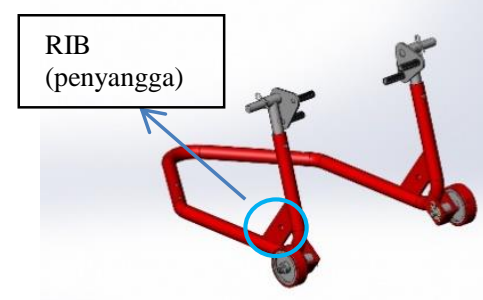

Gambar 2. Salah satu desain paddock stand Sumber: www.grabcad.com



(a)

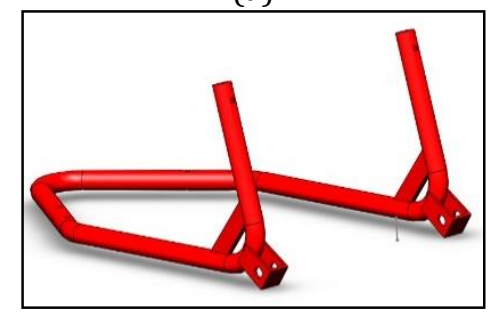

(b)

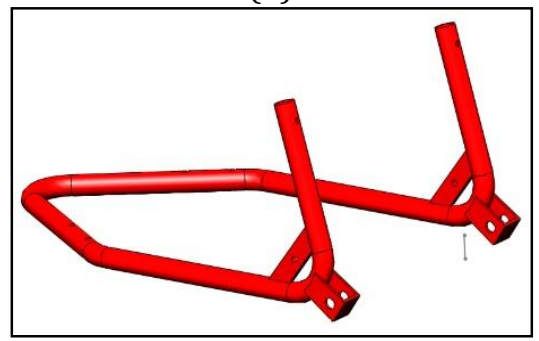

(c)

Gambar 3. Krangka paddock stand (a) tanpa penyangga (b) dengan penyangga, (c) dengan lubang pada penyangga

Dari ketiga bentuk krangka paddock stand dilakukanlah simuasi dengan menggunakan bantuan numerical software. Lubang shaft dan bagian ujung dari paddock stand diasumsikan sebagai tumpuan jepit. Sedangkan bagian atas dari paddock stand diberikan gaya total sebesar $87 \mathrm{Kg}$ dengan arah vertical sebagai pemodelan dari berat kendaraan yang bersandar. Adapun semua kondisi batas (boundary condition) ini dimasukan ke dalam numerical software sebagaimana Gambar 4 dibawah.



Gambar 4. Boundary Condition dari krangka Paddock Stand

Dari simulasi dengan numerical software diperoleh letak dan nilai tegangan maksimum yang bekerja pada paddock stand, baik untuk pddock stand tipe 1, tipe 2, maupun tipe ketiga. Setelah didapakna nilai tegangan maksimum pada ketika tipe paddock stand, maka lagkat selanjutnya adalah melakukan optimasi dimensi. Proses optimasi dimensi dilalukan dengan mencari dimensi terkecil dari pipa krangka padock stand, sedemikian hingga tetap aman digunakan. Adapun kriteria aman ini diperoleh dengan membandingkan antara antara tegangan yield material dengan tegangan maksimum paddock stand.Adapun persamaan yang digunakan adalah sebagai berikut:

$$
N=\frac{s_{y p}}{s_{m}}
$$

(aaron d. deutschman, 1979)

Dengan $N$ adalah angka keamanan; $S_{y p}$ adalah yild point material; dan $S_{m}$ adalah tegangan maksimum yang bekerja pada paddock stand.

Diharapkan bahwa perbandingan nilai yield point material terhadap tegangan maksimum paddock stand adalah sama dengan nilai angka keamanan yang diijinkan.

Adapun data terkait nilai angka keamanan yang diijinkan pada beberapa kondisi pembebanan ditunjukan sebagaimana pada Tabel 1 di bawah. 
Tabel 1. Angka keamanan pada beberapa kondisi pembebanan (aaron d. deutschman, 1979)

\begin{tabular}{|c|c|}
\hline $\begin{array}{c}\text { Besar Angka } \\
\text { Keamanan }\end{array}$ & Keterangan \\
\hline $1,25-1,5$ & $\begin{array}{l}\text { Untuk kondisi yang selalu } \\
\text { terkontrol, mengalami gaya } \\
\text { dan beban yang dapat } \\
\text { diketahui dg sangat akurat. }\end{array}$ \\
\hline $1,5-2$ & $\begin{array}{l}\text { Untuk kondisi dimana } \\
\text { material dapat diketahui, } \\
\text { kondisi lingkungan yang } \\
\text { tetap, mengalami gaya dan } \\
\text { beban yang dapat dicari } \\
\text { dengan segera }\end{array}$ \\
\hline $2-2,5$ & $\begin{array}{l}\text { Untuk material yang secara } \\
\text { umum dioperasikan di } \\
\text { lingkungan } \text { biasa } \\
\text { mengalami dan } \\
\text { tekanan beban } \\
\text { ditentukan }\end{array}$ \\
\hline $2,5-3$ & $\begin{array}{l}\text { untuk material yang jarang } \\
\text { digunakan atau rapuh/brittle } \\
\text { di bawah kondisi lingkungan, } \\
\text { beban, dan tegangan rata- } \\
\text { rata. }\end{array}$ \\
\hline $3-4$ & $\begin{array}{l}\text { untuk bahan material yang } \\
\text { belum pernah dicoba untuk } \\
\text { digunakan, dalam kondisi } \\
\text { lingkungan, beban dan } \\
\text { tegangan rata-rata. }\end{array}$ \\
\hline $3-6$ & $\begin{array}{l}\text { Mstrtisl ysng mengalami } \\
\text { beban impact/kejut }\end{array}$ \\
\hline
\end{tabular}

\section{HASIL DAN PEMBAHASAN 3.1 HASIL SIMULASI}

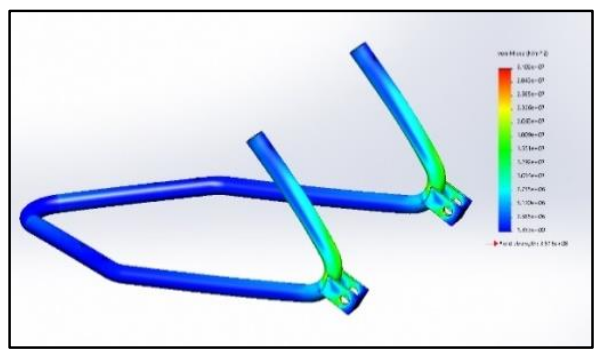

(a)

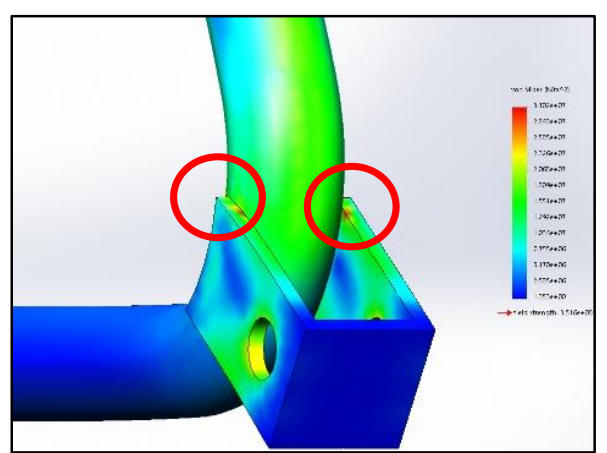

(b)

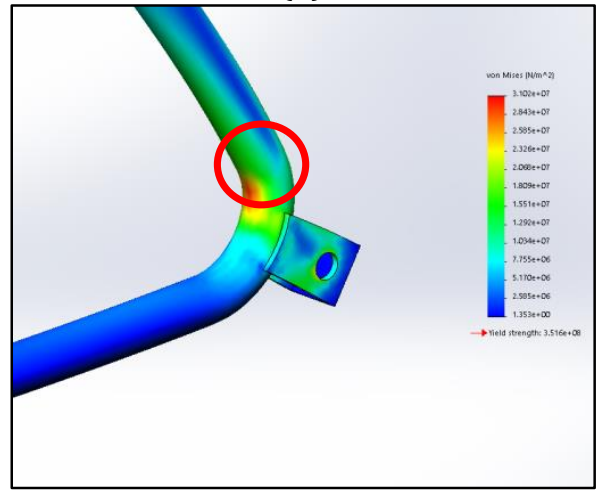

(c)

Gambar 5. Hasil Simulasi tanpa RIB (a), letak titik kritis 1 (b), dan letak titik kritis 2 (c)

Gambar 5 memperlihatkan hasil simulasi dengan menggunakan simulasi software. Dari gambar tersebut diperlihatkan bahwa besar tegangan maksimum yang berkerja pada paddock stand adalah sebesar 31,02 MPa. Adapun letak dari tegangan maksimum yang terjadi adalah pada bagian dalam dari siku paddock stand. Titik lain yang mengalami tegangan maksimum adalah pada bagian sambungan antara krangka paddock stand dan tempat dudukan poros. Dengan demikian kedua titik in merupakan titik yang paling rawan untuk menjadi titik awal kerusakan.

Untuk memperkecil besar dari tegangan maksimum yang terjadi pada siku bagian dalam, maka diberikanlah RIB sebagaimana pada Gambar 6. Dari hasil simulasi yang dilakukan menunjukan bahwa besar dan letak dari tegangan maksimum menjadi berubah. Adapun tegangan maksimum yang terjadi terletak pada perbatasan antara RIB dengan krangka paddock stand yaitu sebesar 27,5 MPa. Konsentrasi tegangan pada area lassan menjadi penyebab terjadinya tegangan maksimum pada perbatasan antara krangka paddock stand dan RIB. 
Pada hasil simulasi ditunjukan pula bahwa tegangan yang terjadi pada bagian tengah dari RIB masih relative kecil. Sehingga penambahan lubang pada RIB berakibat pada tidak berubahnya letak dan nilai dari tegangan maksimum sebagaimana pada Gambar 7.

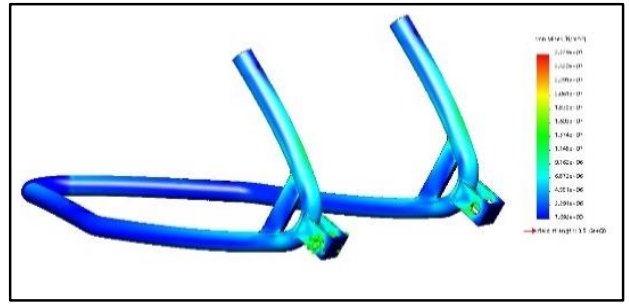

(a)

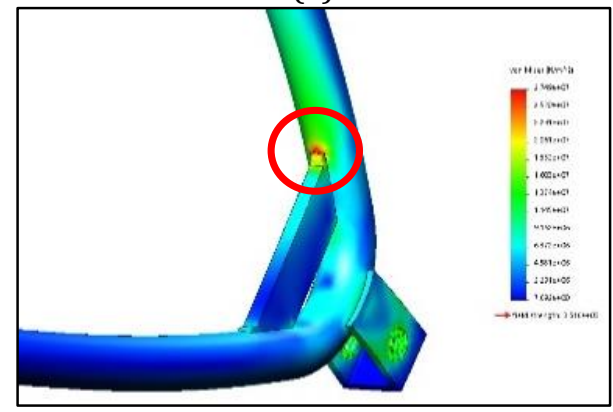

(b)

Gambar 6. Hasil Simulasi RIB (a) dan letak titik kritis (b)

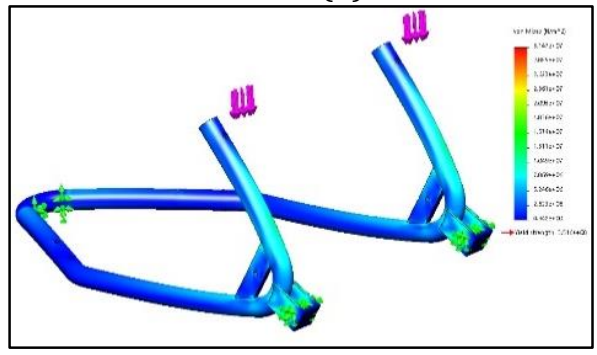

(a)

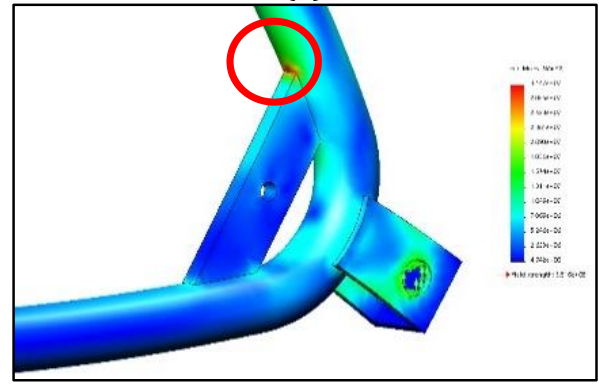

(b)

Gambar 7. Hasil Simulasi RIB dengan lubang (a) dan letak titik kritis (b)

\subsection{OPIMASI DIAMETER PIPA PADDOCK STAND}

Dalam penelitian ini Optimasi dilakukan untuk mendapatkan diameter pipa paddock stand yang terbaik. Pada optimasi dimensi ini diperoleh dimensi/ diameter pipa yang terkecil dari paddock stand, sedemikian hingga masih mampu untuk menahan beban dari kendaraan yang disandarkan. Dengan merujuk pada table 1, dimana paddock stand ini digunakan pada kondisi statis, maka optimasi diameter pipa dilakukan dengan beracuan bahwa nilai angka keamanan yang diperoleh nantinya adalah sebesar 2,5. Dengan diperoleh diameter terkecil, maka diharapkan biaya pembelian material paddock stand dapat ditekan, dan berakibat pada penekanan biaya produksi.

Hasil simulasi paddock stand menunjukan bahwa tegangan maksimum tertinggi terjadi pada paddock stand tanpa RIB. Adapun besar tegangan yang terjadi adalah sebesar 31,02 MPa. Tegangan ini tentu masih berada jauh dari yield point material yaitu sebesar 351,5 MPa. Dengan memasukan kedua nilai parameter ini kedalam persamaan 1, maka diperoleh nilai angka keamanan sebesar 11,4. Sedangkan apabila merujuk pada Tabel 1, maka angka keamanan yang harusnya diberikan pada kondisi operasi dari paddock stand adalah 2.5. perbedaan nilai angka keamanan antara teori dan simuasi ini menunjukan bahwa paddock stand tanpa RIB memiliki kekuatan yang jauh lebih tinggi daripada yang diharapkan (terlalu kuat), sehingga perlu untuk dilakukan optimasi dimensi

Optimasi dimensi dilakukan dengan mereduksi dimensi pipa. Untuk mendapatkan dimensi ini dilakukan trial and error pada diameter pipa sehingga diperoleh nilai tegangan yang masih diijinkan. Adapun besar nilai tegangan ijin dapat dihitung dengan memodifikasi persamaan 1 menjadi sebagai berikut

$$
S_{m}=\frac{S_{y p}}{N}
$$

Dengan memasukan nilai $\mathrm{N}=2,5$; nilai Syp $=351$ MPa; maka

$$
\begin{aligned}
S_{m} & =\frac{351 \mathrm{MPa}}{2,5} \\
S_{m} & =140,4 \mathrm{MPa}
\end{aligned}
$$

Dengan beracuan pada nilai tegangan ijin diatas maka diperoleh diameter krangka paddock stand yang paling optimal adalah sebesar $13,1 \mathrm{~mm} \approx$ $13 \mathrm{~mm}$. adapun besar tegangan maksimum yang 
terjadi adalah sebesar 136,9 MPa. Dengan menggunakan pipa dengan diameter ini lendutan yang dihasilkan saat paddock stand menerima beban juga masih relative rendah, yaitu hanya 2,4 mm (Gambar 8b).

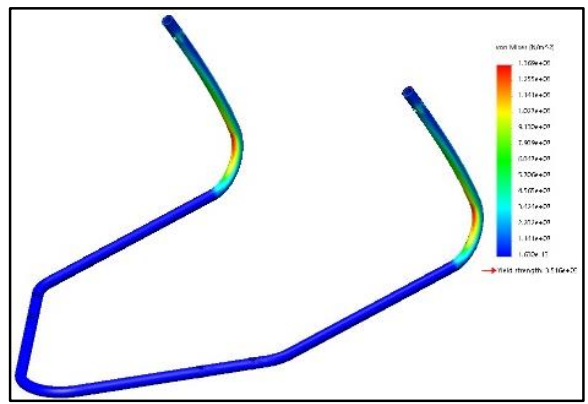

(a)



(b)

Gambar 8. Hasil simulasi pada diameter optimal (a) tegangan vonmisses (b) lendutan

\section{KESIMPULAN}

Dari penelitian ini dapat disimpulkan bahwa pemberian RIB secara efektif dapat mengurangi tegangan yang terjadi pada siku bagian dalam dari krangka paddock stand. Dengan melakukan optimasi desain dari paddock stand diperoleh diameter pipa optimal yang diperoleh adalah sebesar $13 \mathrm{~mm}$. adapun lendutan terbesar yang diperoleh pada kondisi optimal adalah sebesar4 $\mathrm{mm}$, dengan nilai tegangan maksimal yang diperoleh sebesar 136,9 MPa.

\section{DAFTAR PUSTAKA}

Aaron d. deutschman. (1979). Machine Design.

https://doi.org/10.11646/zootaxa.403 3.1.2

Anggono, W., Sanjaya, A., Suprianto, F. D., Wijaya, T. P., Teknik, J., Universitas, M., \& Petra, K. (2014). OPTIMASI JUMLAH COMPARTMENT TANGKI TRUK $\begin{array}{llr}\text { BAHAN BAKAR } & \text { MINYAK } & \text { DENGAN } \\ \text { MENGGUNAKAN } & \text { FINITE } & \text { ELEMENT } \\ \text { APPLICATION. } & \text { Seminar } & \text { Nasional }\end{array}$ Teknik Mesin 9, 43-46. surabaya: Petra University.

Arief, T. M. (2014). Analisis Kekuatan Struktur Pallet Menggunakan Metode Elemen Hingga. Jurnal Energi Dan Manufaktur Vol.7, No.1, April 2014: 1118, 7(1), 63-72.

Covill, D., Begg, S., Elton, E., Milne, M., Morris, R., \& Katz, T. (2014). Parametric finite element analysis of bicycle frame geometries. Procedia Engineering, 72, 441-446.

https://doi.org/10.1016/j.proeng.201 4.06.077

Fahd Riyal Pris, Budhi M Suyitno, \& Amin Suhadi. (2019). Analisis Kekuatan Velg Aluminium Alloy 17 Inc Dari Berbagai Desain Menggunakan Metode Finite Element Analysis (Fea). Teknobiz: Jurnal Ilmiah Program Studi Magister Teknik Mesin, 9(2), 33-39. https://doi.org/10.35814/teknobiz.v9i 2.558

Metode, M., \& Hingga, E. (2011). 50 ANALISA TEGANGAN-REGANGAN PRODUK TONGKAT LANSIA DENGAN MENGGUNAKAN METODE ELEMEN HINGGA Santoso Mulyadi 1. 4, 50-58.

Nugroho, S. A. (2018). Komparasi R25 dengan Ninja 250 dan CBR250RR. Retrieved from https://otomotif.kompas.com/read/20 18/10/12/104034715/komparasir25-dengan-ninja-250-dancbr250rr?page=all\#page 1

Ren, Y., Yu, Y., Zhao, B., Fan, C., \& Li, H. (2017). Finite Element Analysis and Optimal Design for the Frame of SX360 Dump Trucks. Procedia Engineering, 174, 638-647. https://doi.org/10.1016/j.proeng.201 7.01.201

Wandono, F. A. (2017). Permodelan Metode Elemen Hingga UNTUK Menentukan 
Tegangan Von Mises Pada As Roda Lsu05. Seminar Nasional Iptek Penerbangan Dan Antariksa XXI, 222231.

Wandono, F. A., \& Syah, A. H. N. (2017). Prediksi Kekuatan Struktur Alat Uji Getaran Engine Lsu Series Menggunakan Metode Elemen Hingga (Strength Prediction of the Engine Vibration Test Stand of Lsu Series Using Finite Element Method). Jurnal Teknologi Dirgantara, 15(1), 71. https://doi.org/10.30536/j.jtd.2017.v1 5.a2505 